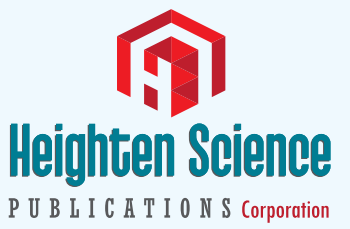

ISSN

2576-9529

\title{
Chronic Kidney Disease: A single day screening on World Kidney Day for five consecutive years
}

\author{
Rai Pradeep K*, Rai Punam² and Bedi Sonam ${ }^{3}$ \\ 'Senior Consultant Nephrologist, Department of Nephrology, Opal Hospital, Kakarmatta, \\ Varanasi- 221004, India \\ ${ }^{2}$ Senior Clinical Physiologist \& Infertility Expert, Opal Hospital, Kakarmatta, Varanasi- 221004, \\ India \\ ${ }^{3}$ Senior Data Analyst, Department of Medicine, Institute of Medical Sciences, Banaras Hindu \\ University, Varanasi- 221005, India
}

\begin{abstract}
*Address for Correspondence: Dr. Pradeep Kumar Rai, M.B.B.S, MD, DM, D.N.B, F.A.S.N, Senior Consultant Nephrologist, Department of Nephrology, Opal Hospital, Kakarmatta, Varanasi221004, India, Tel: +91-9336913486; Email: pradnephro@gmail.com; pradeepk.rai@gmail.com

Submitted: 26 November 2018

Approved: 11 March 2019

Published: 12 March 2019
\end{abstract}

Copyright: ๑ 2019 Rai PK, et al. This is an open access article distributed under the Creative Commons Attribution License, which permits unrestricted use, distribution, and reproduction in any medium, provided the original work is properly cited

Keywords: Chronic kidney disease; Serum creatinine; Albuminuria; Hypertension; Diabetes mellitus; Smoking

Check for updates

\section{Abstract}

Introduction: Chronic kidney disease is a costly and burdensome public health concern. Delayed recognition and treatment of CKD may predispose patients to unfavorable future outcomes and burden the healthcare services. The early detection of disease via screening programs is widely recommended. The present study is a hospital camp-based screening for detecting patients with chronic kidney disease in Varanasi from 2014-18.

Methods: The study subjects constituted 436 apparently healthy adults (age $\geq 18$ years) of Varanasi. Information on socio-demographic profile, personal characteristics and clinical investigations were recorded. Stepwise binary logistic regression analysis was applied to find the significant predictors of chronic kidney disease.

Results: Median age of the study subjects was 40.5 years. There were $39.7 \%$ males and $60.3 \%$ females. Chronic kidney disease was found in $23.9 \%$ subjects. Underweight, diabetes mellitus, hypertension, smoking status and higher creatinine levels came out as significant predictors of chronic kidney disease.

Conclusion: We screened apparently healthy individuals and found very high percentages of chronic kidney disease and its predictors. Henceforth, understanding the preventable and modifiable risk factors of chronic kidney disease becomes a prerequisite to intervene before risk populations reaches to irreversible stages of adverse future outcomes.

\section{Introduction}

Chronic kidney disease (CKD) is a costly and burdensome public health concern [1]. Delayed recognition and treatment of CKD may predispose patients to unfavorable future outcomes. The health care costs and economic burden of CKD are huge and not sustainable even in advanced Western countries [3]. Hence, early detection of disease via screening programs is widely recommended [3]. We conducted a hospital campbased screening of general population on World Kidney Day for five consecutive years (2014-18) for detecting patients with CKD.

\section{Methods}

\section{Data characteristics}

The study subjects constituted 436 apparently healthy adults of Varanasi. Screening was done as a part of World Kidney Day celebration, in the month of March, from 2014- 
2018, a total of five consecutive years, every year according to the theme of World Kidney day. Individuals aged $\geq 18$ years of age were invited to participate in the study through electronic media and newspapers. Approval to conduct the screening camp was obtained from the Ethical and Research Committee of Opal Hospital. All the participants provided informed consent. Subjects with symptomatic acute kidney injury (AKI) or transplanted kidneys were excluded from the screening.

Information on socio-demographic profile and personal characteristics like, age, sex, height, weight, smoking status, history of diabetes mellitus (DM) and hypertension (HTN), familial history of kidney disease was interrogated. Lab and clinical investigations like, random blood sugar (RBS), urinalysis and serum creatinine levels were recorded. Systolic and diastolic blood pressures (BP) were measured on the day of screening.

\section{Definitions of variables}

All the continuous variables were converted into categories for appropriate clinical interpretation. Age was divided into 3 categories (in complete years), e.g. young adults $(<45)$, middle aged adults (45-65) and elderly $(>65)$. Gender was classified into two, males and females. Body mass index (BMI) was divided into 4 categories (in $\left.\mathrm{kg} / \mathrm{m}^{2}\right)$ : underweight $(<18.50)$, normal $(18.50-24.99)$, overweight $(25.00-29.99)$ and obese (>29.99).

Diabetes was defined as the use of glucose lowering medicine and/or RBS $\geq 200$. HTN was defined as the use of any anti-hypertensive and/or based on systolic (SBP $>140$ ) and/or diastolic BP (DBP >90). Smoking status, DM, HTN, family history of kidney disease and albuminuria was dichotomized as: yes (present) and no (absent). Serum creatinine level $(\mathrm{mg} / \mathrm{dl})$ was divided in 2 groups: normal $(<1.30)$ and abnormal $(\geq 1.30)$.

A urine dipstick (Medi-Test Combi 9-Macherey Nagel, Duren, Germany) was performed for each individual. Two millilitres of blood sample was collected from each participant through venepuncture to investigate for serum creatinine level.

The outcome variable was presence of CKD. CKD was based on estimated glomerular filtration rate (eGFR) levels and albuminuria. GFR was calculated using the Modification of Diet in Renal Disease (MDRD) equation [4] for adults. All individuals with a positive (CKD) test result were referred to the nephrologists, but they were not followed up in future course of time.

Albuminuria was regarded as significant if $1+$ and above [5]. CKD stages were defined as: stage 1 if eGFR $\geq 90$ and albuminuria present; stage 2 if eGFR= 60 to 89 and albuminuria present; stage 3 if eGFR= 30 to 59; stage 4 if eGFR= 15 to 29; and stage 5 if eGFR $<15$ according to the National Kidney Foundation (NKF) Kidney Disease Outcomes Quality Initiative (KDOQI) guidelines [6].

\section{Statistical analysis}

All the statistical analysis was performed on Stata/IC V10.1 (StataCorp. College Station, TX, USA). Normality of the continuous variables was checked using Kolmogorov Smirnov test. For the continuous non-parametric data, median (inter-quartile range (IQR)) were reported. Proportions were given for categorical variables. The continuous variables were categorized and the association of each variable with the outcome was seen separately using Pearson's chi square test at $5 \%$ level of significance.

Further, a two-step procedure was used to select the most appropriate and parsimonious predictive model for the predictors of CKD. Initially bi-variable binary logistic regression analysis was performed. The predictors significant in bi-variable analysis (at 10\%) were taken into the final multi-variable binary logistic regression analysis. Predictors were also tested for presence of potential confounding and interaction. Stepwise backward likelihood Ratio logistic regression was performed to 
eliminate the insignificant predictors of CKD in multi-variable logistic regression. A p-value of 0.05 was used as a threshold for predictors to contribute significantly. $95 \%$ confidence intervals (CI) of the estimated odds ratio (OR) was obtained along with the corresponding p-values.

\section{Results}

A total of 436 participants were screened and clubbed together for analyses. The profile of the participants is presented in table 1. Median age of the study subjects was $40.5(\mathrm{IQR}=32-55)$ years. There were $173(39.7 \%)$ males and $263(60.3 \%)$ females. The median BMI was $26.4(\mathrm{IQR}=22.9-30.3) \mathrm{kg} / \mathrm{m}^{2}$. Median SBP and DBP was $126(110$ 140 ) and 80 (70-88) $\mathrm{mm} \mathrm{Hg}$ respectively. CKD was found in $23.9 \%$ subjects. GFR <60 $\mathrm{ml} / \mathrm{min} / 1.73 \mathrm{~m}^{2}$ was seen in $6.7 \%$ subjects.

Approximately equal proportion of CKD cases (30.6\% and 28.6\%) were laying in the middle aged and elderly subjects whereas, $19.2 \%$ young adults were having CKD. CKD was significantly associated with age of the subjects ( $p=0.029)$. Less than onethird (30.6\%) males and it's almost half (i.e. 19.4\%) of the females were suffering with CKD. Gender was significantly associated with CKD ( $p=0.007)$. Half $(50 \%)$ of underweight subjects were suffering with CKD, followed by obese (29\%), normal BMI $(22.1 \%)$ and little less in overweight (19.1\%) subjects. BMI was highly associated with CKD ( $\mathrm{p}=0.003)$.

Smoking was highly associated with CKD ( $\mathrm{p}<0.001) .8$ out of 9 smokers were cases

\begin{tabular}{|c|c|c|c|c|}
\hline Characteristics & $\mathbf{N}$ & $\%$ Distribution & $\%$ CKD & $\begin{array}{c}\text { Pearson's } x^{2} \\
\text { p value }\end{array}$ \\
\hline \multicolumn{5}{|l|}{ Age (years) } \\
\hline$<45$ & 250 & 57.3 & 19.2 & \multirow{3}{*}{0.029} \\
\hline $45-65$ & 144 & 33.0 & 30.6 & \\
\hline$>65$ & 42 & 9.6 & 28.6 & \\
\hline \multicolumn{5}{|l|}{ Gender } \\
\hline Male & 173 & 39.7 & 30.6 & \multirow{2}{*}{0.007} \\
\hline Female & 263 & 60.3 & 19.4 & \\
\hline \multicolumn{5}{|l|}{ BMI } \\
\hline Underweight & 30 & 7.9 & 50.0 & \multirow{4}{*}{0.003} \\
\hline Normal & 113 & 29.8 & 22.1 & \\
\hline Overweight & 136 & 35.9 & 19.1 & \\
\hline Obese & 100 & 26.4 & 29.0 & \\
\hline \multicolumn{5}{|l|}{ Smoking } \\
\hline Yes & 9 & 2.3 & 88.9 & \multirow{2}{*}{$<0.001$} \\
\hline No & 387 & 97.9 & 21.7 & \\
\hline \multicolumn{5}{|c|}{ Family history of renal disease } \\
\hline Yes & 10 & 2.5 & 40.0 & \multirow{2}{*}{0.259} \\
\hline No & 396 & 97.5 & 23.5 & \\
\hline \multicolumn{5}{|l|}{ DM } \\
\hline Yes & 46 & 10.6 & 63.0 & \multirow{2}{*}{$<0.001$} \\
\hline No & 386 & 89.4 & 19.4 & \\
\hline \multicolumn{5}{|l|}{ HTN } \\
\hline Yes & 128 & 33.1 & 35.2 & \multirow{2}{*}{0.001} \\
\hline No & 259 & 66.9 & 19.7 & \\
\hline \multicolumn{5}{|l|}{ Albuminuria } \\
\hline Yes & 82 & 18.8 & 100.0 & \multirow{2}{*}{$<0.001$} \\
\hline No & 354 & 81.2 & 6.2 & \\
\hline \multicolumn{5}{|c|}{ Serum creatinine $(\mathrm{mg} / \mathrm{dl})$} \\
\hline$<1.30$ & 409 & 93.8 & 22.0 & \multirow{2}{*}{$<0.001$} \\
\hline$\geq 1.30$ & 27 & 6.2 & 51.9 & \\
\hline \multicolumn{5}{|c|}{ eGFR (ml/min/1.73m²) } \\
\hline$\geq 90$ & 243 & 55.7 & 25.1 & \multirow{4}{*}{$<0.001$} \\
\hline $60-89$ & 164 & 37.6 & 8.5 & \\
\hline $30-59$ & 27 & 6.2 & 100.0 & \\
\hline $15-29$ & 2 & 0.5 & 100.0 & \\
\hline
\end{tabular}


of CKD. Family history of kidney disease was found in only 10 subjects (2.5\%), of which less than half (40\%) were cases of CKD but the association was insignificant ( $\mathrm{p}=0.259)$. Median RBS level was 105 (IQR=92-120) mg/dL. 46 (10.6\%) and 128 (33.1\%) subjects were diabetics and hypertensive, of which $63 \%$ and $35.2 \%$ were cases of CKD with significant association ( $\mathrm{p}<0.001$ and $\mathrm{p}=0.001$ respectively).

Median serum creatinine level was $0.8(\mathrm{IQR}=0.7-1.0) \mathrm{mg} / \mathrm{dl}$. Further, $6.2 \%$ subjects were having higher creatinine levels $(\geq 1.30)$, of which more than half $(51.9 \%)$ were the cases of CKD. Clearly, CKD was significantly associated with creatinine levels ( $p$ $<0.001)$. Albuminuria was found positive in $82(18.8 \%)$ subjects, of which all were CKD cases. Median eGFR level was $94(\mathrm{IQR}=73-117) \mathrm{ml} / \mathrm{min} / 1.73 \mathrm{~m}^{2}$. It was further divided into 5 categories and was found highly associated with CKD $(\mathrm{p}<0.001)$.

In the bi-variable logistic regression analysis age, gender, BMI, DM, HTN, smoking status and serum creatinine came out to be individual risk factors for CKD (Table 2). All these predictors were considered together in multi-variable analysis.

Through the multi-variable model (Table 2), we found that diabetes was associated with 6-fold increase in the odds of development of CKD (OR: 6.646, 95\% CI: 3.13814.076). Hypertensive subjects were twice (OR: 1.829, 95\% CI: 1.043-3.206) more likely to be case of CKD. Subjects with higher serum creatinine levels were having almost 4 times higher risk of progressing to chronic kidney disease (OR: 3.926, 95\% CI: 1.438-10.715). Further, we found underweight subjects were associated with doubling the odds of developing CKD (OR: 2.690, 95\% CI: 1.058-6.838) compared to normal BMI subjects. Highest risk of CKD development was associated with the smokers (OR: 34.661, 95\% CI: 3.933-305.473). Overall predictability of the logistic model was $80.6 \%$.

\begin{tabular}{|c|c|c|}
\hline \multirow[t]{2}{*}{ Characteristics } & \multicolumn{2}{|c|}{$\begin{array}{c}\text { P-values } \\
\text { OR (95\% Cl of OR) }\end{array}$} \\
\hline & Bi-variable predictors & Multi-variable predictors \\
\hline \multicolumn{3}{|l|}{ Age in years (Ref: <45) } \\
\hline $45-65$ & $\begin{array}{c}.011 \\
1.852(1.153-2.975)\end{array}$ & * \\
\hline$>65$ & $\begin{array}{c}.168 \\
1.683(.803-3.527)\end{array}$ & * \\
\hline \multicolumn{3}{|l|}{ Gender (Ref: Female) } \\
\hline Male & $\begin{array}{c}.007 \\
1.836(1.177-2.865)\end{array}$ & * \\
\hline \multicolumn{3}{|l|}{ BMI (Ref: Normal) } \\
\hline Underweight & $\begin{array}{c}.003 \\
3.520(1.516-8.173)\end{array}$ & $\begin{array}{c}.038 \\
2.690(1.058-6.838)\end{array}$ \\
\hline Overweight & $\begin{array}{c}.559 \\
.832(.449-1.541)\end{array}$ & $\begin{array}{c}.080 \\
.525(.255-1.081)\end{array}$ \\
\hline Obese & $\begin{array}{c}.251 \\
1.438(.774-2.672)\end{array}$ & $\begin{array}{c}.625 \\
.836(.408-1.713)\end{array}$ \\
\hline \multicolumn{3}{|l|}{ DM (Ref: No) } \\
\hline Yes & $\begin{array}{c}.000 \\
7.074(3.694-13.545)\end{array}$ & $\begin{array}{c}.000 \\
6.646(3.138-14.076)\end{array}$ \\
\hline \multicolumn{3}{|l|}{ HTN (Ref: No) } \\
\hline Yes & $\begin{array}{c}.001 \\
2.211(1.375-3.555)\end{array}$ & $\begin{array}{c}0.035 \\
1.829(1.043-3.206)\end{array}$ \\
\hline \multicolumn{3}{|l|}{ Smoking (Ref: No) } \\
\hline Yes & $\begin{array}{c}.002 \\
28.857(3.559-233.975)\end{array}$ & $\begin{array}{c}.001 \\
34.661(3.933-305.473)\end{array}$ \\
\hline \multicolumn{3}{|c|}{ Family history of renal disease (Ref: No) } \\
\hline Yes & $\begin{array}{c}.237 \\
.460(.127-1.666)\end{array}$ & * \\
\hline \multicolumn{3}{|l|}{ Creatinine (Ref: <1.30) } \\
\hline$\geq 1.30$ & $\begin{array}{c}.001 \\
3.817(1.732-8.413)\end{array}$ & $\begin{array}{c}.008 \\
3.926(1.438-10.715)\end{array}$ \\
\hline
\end{tabular}




\section{Discussion}

Chronic Kidney Disease is an enormous public health issue, the tide of which continues to inexorably rise [7]. In the 2015 Global Burden of Disease Study, kidney disease was the $12^{\text {th }}$ most common cause of death, accounting for 1.1 million deaths worldwide [8]. Overall CKD mortality has increased by $31.7 \%$ over the last 10 years, making it one of the fastest rising major causes of death, alongside diabetes [8]. In the same study, CKD ranked as the $17^{\text {th }}$ leading cause of global years loss of life, an $18.4 \%$ increase since 2005, and the third largest increase of any major cause of death [8].

Due to its asymptomatic nature, CKD is frequently detected at an advanced stage, resulting in the loss of opportunities to influence its course and outcome. In the present study, we described the prevalence patterns and association with some known risk factors of CKD among general population of Varanasi using screening data, collected on a single day for 5 consecutive years. We recruited apparently healthy population who voluntarily participated in the hospital based screening camp, thus providing better insight about the asymptomatic kidney disease in the society. Similar single center hospital, regional, population and community based studies have been performed on target population earlier [5,9-15]. The objective of the current study was to identify what risk factors, present in the community, are associated with the development of CKD and which are remediable or potentially modifiable, in order to detect early CKD and intervene at the earliest possible stage.

Our study reported overall a very high prevalence of CKD as $23.9 \%$, an overestimate compared to global [16] and Indian perspective [15]. Although higher prevalence $(>30 \%)$ have been accounted for north Indian cities like Delhi, Kanpur, Ludhiana etc. in the SEEK India cohort [15]. Indian researchers seem to follow varied diagnostic criteria for CKD [17] depending upon different cut-offs for serum creatinine [9] or proteinuria (Baumgarten and Gehr 2011) and/or GFR [18], levels which could be a probable reason for the prevalence discrepancies. The standard criteria for CKD detection refers to reduction in eGFR levels and the presence of albuminuria over 3 months [19], but our study was a cross sectional one hence, CKD case detection was made based on single day measurement. Prevalence of CKD stages 1, 2, 3, and 4 was $14 \%, 3.2 \%, 6.2 \%$ and $0.5 \%$, respectively i.e. prevalence of Stage-3 CKD or worse in the present study was $6.7 \%$, approximately equivalent to other standard published reports of India [15,17], however, lower than global figures [16].

Diabetes and hypertension are the key risk factors of CKD in all high-income and middle-income countries, and also in many low-income countries [20]. Unsurprisingly our data also showed that diabetics and hypertensive were more likely to be a case of new-onset kidney disease. More than one-third (35.2\%) hypertensive and half of diabetics (63\%) were suffering with CKD.

Smoking can increase the CKD risk through proinflammatory state, oxidative stress, prothrombotic shift, endothelial dysfunction, glomerulosclerosis and tubular atrophy [21]. Smoking, being a well-known risk factor for many diseases, is also proven to play an important role in renal diseases. Community based studies have shown that cigarette smoking is a risk factor for the development and progression of CKD [22]. In the present analysis also, smoking was highly associated with CKD development. There is growing evidence that smoking increases the risk of albuminuria/proteinuria along with renal functional deterioration. In the present study, 88.9\% smokers were having proteinuria $(\mathrm{p}<0.001)$. In the past few years the knowledge about the renal risks of smoking has expanded rapidly [23], this study further added on the similar evidences.

In present study, subjects were between $19-90$ years comprising $9.6 \%$ elderly subjects ( $>65$ years) and therefore, vulnerable to the age related glomerulosclerosis and decline in kidney function. Nearly $60 \%$ middle-aged and elderly subjects were 
found to be suffering with CKD ( $\mathrm{p}<0.05)$. Clearly, aging being a strong non-modifiable risk factor for CKD [24,25]. Although middle aged adults and elderly were more likely to be a case of CKD compared to younger counterparts in bi-variable analysis; age was excluded from the multivariable analysis. Studies report after the age of 30 years, GFR progressively declines at an average rate of $8 \mathrm{~mL} / \mathrm{min} / 1.73 \mathrm{~m}^{2}$ per decade [26]. Although, approximately one-third of the population does not experience a decline in GFR with age [27]. There is ongoing debate as to whether this age-related GFR decline is normal or pathological and so there always remains a question about the distinction between early CKD and normal age related decline in renal function [28]. In the present study, age category was significantly associated with other risk factors like, BMI, DM, and HTN thus influencing the occurrence of CKD. Further work is required to determine whether renal impairment in elderly subjects is associated with or causes other conditions.

Studies have emphasized CKD being more prevalent among males than females [29]. Our analysis revealed nearly 1.8 times higher risk of CKD in males compared to females in bi-variable analysis, although we did not find any gender differences with CKD in multi-variable analysis.

We found underweight subjects were twice more likely to suffer with CKD compared to normal BMI subjects, which could be due to the weaker immunity of underweight subjects and abnormalities induced by an inadequate diet, and other biomedical traits which invite vulnerability towards CKD. Lower BMI has been previously associated with greater mortality in patients with CKD [30]. Concurrently in this study 50\% underweight subjects were CKD sufferers $(\mathrm{p}=0.003)$. A high body mass index is one of the strongest and independent risk factors for new-onset CKD [31,32], plenty many published literature points on obesity being a strong risk factor of CKD but in our study high BMI did not come significantly associated with CKD occurrence. Furthermore, the link between BMI and CKD should be interpreted with caution due to the potential confounding effect of diabetes and hypertension and other chronic illnesses [33] since studies provide evidences about $30 \%$ of obese patients seem to be protected against obesity-related metabolic complications [34], although in our study there was no confounding and interaction between the variables, however, BMI was associated with DM and HTN as well ( $p<0.05)$. In summary, the bulk of evidence suggests BMI is an important, modifiable, independent risk factor for the development of CKD.

Serum creatinine is an important biomarker of kidney function [35] and used as a convenient index of kidney function [36]. In the present study, 6.2\% subjects had serum creatinine level $\geq 1.30 \mathrm{mg} / \mathrm{dl}$, of which more than half (51.9\%) were identified with CKD. Logistic regression analysis also depicted almost 4 times higher risk of CKD development in subjects with higher serum creatinine levels, which is in consensus with published literature [37]. Henceforth, subjects with even minimal creatinine elevation are suggested for frequent health checkups as it may indicate presence of clinically significant kidney disease which could be intervened adequately well in time to prevent further progression to higher stages of CKD and ESRD.

The ongoing explosion of chronic diseases in India like CKD, cardio vascular diseases (CVD) can be attributed to multiple lifestyle changes of the modern generation and increase in their risk factors. The key modifiable risk factors for CKD in the community are BMI, diabetes mellitus, hypertension, smoking status and serum creatinine levels. The principle non-modifiable risk factors are age, gender and a family history of kidney disease. The presence of any one of these risk factors is associated with a higher risk of developing CKD. Similar findings have been reported in previous studies $[10,15,21,22,38]$. Furthermore, the presence of CKD is one of the most potent known risk factors for cardiovascular disease, such that individuals with CKD have a 2 to 3 -fold greater risk of cardiac death than age- and sex-matched controls without CKD [39]. Hence, the progression of CKD and related adverse outcomes can be prevented or delayed through early detection and intervening with treatment modalities [11]. 


\section{Limitations}

The data collection was not ongoing; the subjects were screened in a cross sectional way on a single day measure every year. Single day measurements of serum creatinine and urinary markers of kidney damage are likely to overestimate the true prevalence of CKD. The study was conducted at hospital based health camp hence; the study results may not be nationally representative.

\section{Conclusion}

The high and increasing prevalence of CKD has several potential public health and clinical implications. We screened apparently healthy individuals who volunteered to participate in the screening camps and found very high percentages of CKD and also its predictors. One of the main issues is to understand its preventable and modifiable risk factors like diabetes, hypertension, smoking, underweight, so as to intervene before such risk populations reaches to irreversible stage of adverse outcome and thus reduce the load of health care delivery system that are involved in its treatment modalities.

\section{Acknowledgements}

We would like to thank medical officers and staff of Opal hospital: Dr. Shashi Kumar Gupta, Dr Hemant Kumar Rai, Dr. Zafar Raja, Dr. Santosh Mishra, Dr. Surendra Nath Gupta, Mrs. Arti Maurya and Mr. Bansi Dhar Pandey who have helped with evaluation of subjects in the screening camp

\section{Declarations}

Ethics approval and consent to participate:

The subjects who consented to participate in the study were considered.

Opal Hospital Ethics Committee approval was taken before starting the present study.

\section{Informed consent}

Informed consent was obtained from all the subjects.

\section{References}

1. Everett B, Castel LD, McGinnis M, Beresky A, Cane RC Jr, et al. Economic and Clinical Outcomes Resulting From the Stage 4 Chronic Kidney Disease Case Management Quality Improvement Initiative. Prof Case Manag. 2017; 22: 291. Ref.: https://goo.gl/joWb7W

2. Ojo A. Addressing the Global Burden of Chronic Kidney Disease through Clinical and Translational Research. Trans Am Clin Climatol Assoc. 2014; 125: 229-243. Ref.: https://goo.gl/6DzNKh

3. Mendelssohn DC. Coping with the CKD Epidemic: The Promise of Multidisciplinary Team-Based Care. Nephrol Dial Transplant. 2005; 20: 10-12. Ref.: https://goo.gl/W3r8bm

4. Levey AS, Bosch JP, Lewis JB, Greene T, Rogers N, et al. A More Accurate Method to Estimate Glomerular Filtration Rate from Serum Creatinine: A New Prediction Equation. Ann Intern Med. 1999; 130: 461-70. Ref.: https://goo.gl/MdkXrh

5. Ulasi II, ljoma CK, Onodugo OD, Arodiwe EB, Ifebunandu NA, et al. 2013. Towards Prevention of Chronic Kidney Disease in Nigeria: A Community-Based Study in Southeast Nigeria. Kidney International Supplements. 2017; 3: 195-201. Ref.: https://goo.gl/CRpz9b

6. Ketteler M, Block GA, Evenepoel P, Fukagawa M, Herzog CA, et al. Executive Summary of the 2017 KDIGO Chronic Kidney Disease-Mineral and Bone Disorder (CKD-MBD) Guideline Update: What's Changed and Why It Matters. Kidney Int. 2017; 92: 26-36. Ref.: https://goo.gl/RfKNHH

7. Neuen BL, Chadban SJ, Demaio AR, Johnson DW, Perkovic V. Chronic Kidney Disease and the Global NCDs Agenda. BMJ Glob Health. 2017; 2: e000380. Ref.: https://goo.gl/z3ZfYW

8. Wang H, Naghavi M, Allen C, Barber RM, Bhutta ZA, et al. Global, Regional, and National Life Expectancy, All-Cause Mortality, and Cause-Specific Mortality for 249 Causes of Death, 1980-2015: A Systematic Analysis for the Global Burden of Disease Study 2015. The Lancet. 2016; 388: 14591544. Ref.: https://goo.gl/86Yu6C 
9. Agarwal SK, Dash SC, Irshad M, Raju S, Singh R, et al. Prevalence of Chronic Renal Failure in Adults in Delhi, India. Nephrol Dial Transplant. 2005; 20: 1638-1642. Ref.: https://goo.gl/zkKD9D

10. Haroun MK, Jaar BG, Hoffman SC, Comstock GW, Klag MJ, et al. Risk Factors for Chronic Kidney Disease: A Prospective Study of 23,534 Men and Women in Washington County, Maryland. J Am Soc Nephrol. 2003; 14: 2934-2941. Ref.: https://goo.gl/hc9Qbd

11. Ležaić V, Bajčetić S, Peruničić-Peković G, Bukvić D, Dimković N, et al. Screening of Elderly for Chronic Kidney Disease. Kidney Blood Press Res. 2012; 35: 497-503. Ref.: https://goo.gl/FqrKTX

12. Modi GKVM, Jha V. The Incidence of End-Stage Renal Disease in India: A Population-Based Study. Kidney int. 2006; 70: 2131-2133. Ref.: https://goo.gl/bMGC4K

13. Rai PK, Rai P, Bedi S. Prevalence and Risk Factors of Chronic Kidney Disease: A Single Day Screening on World Kidney Day for Four Consecutive Years in Varanasi. Urology \& Nephrology Open Access Journal. 2018; 6: 167-171. Ref.: https://goo.gl/3TqPQe

14. Rai PK, Jindal PK, Rai P, Rai PK, Rai SN, et al. Screening of Chronic Kidney Disease (CKD) in General Population on World Kidney Day on Three Consecutive Years: A Single Day Data. Int J Med Public health. 2014; 4: 167-170. Ref.: https://goo.gl/8ixfzs

15. Singh AK, Farag YM, Mittal BV, Subramanian KK, Reddy SR, et al. Epidemiology and Risk Factors of Chronic Kidney Disease in India-results from the SEEK (Screening and Early Evaluation of Kidney Disease) Study. BMC nephrology. 2013; 14: 114. Ref.: https://goo.gl/Q3WhJ4

16. Hill NR, Fatoba ST, Oke JL, Hirst JA, O'Callaghan CA, et al. Global Prevalence of Chronic Kidney Disease-a Systematic Review and Meta-Analysis. PloS One. 2016; 11: e0158765. Ref.: https://goo.gl/7ph4Jy

17. Varma PP. Prevalence of Chronic Kidney Disease in India-Where Are We Heading? Indian J Nephrol. 2015; 25: 133-135. Ref.: https://goo.gl/fwdfDs

18. Levey AS, Eckardt KU, Tsukamoto Y, Levin A, Coresh J, et al. Definition and Classification of Chronic Kidney Disease: A Position Statement from Kidney Disease: Improving Global Outcomes (KDIGO). Kidney Int. 2005; 67: 2089-2100. Ref.: https://goo.gl/HEvXdc

19. Sherwood M, McCullough PA. Chronic Kidney Disease from Screening, Detection, and Awareness, to Prevention. Lancet Glob Health. 2016; 4: e288-289. Ref.: https://goo.gl/tr7TU2

20. WebsterAC, Nagler EV, Morton RL, Masson P. Chronic Kidney Disease. The Lancet. 2017; 389(10075): 1238-1252. Ref.: https://goo.gl/b8225L

21. KazancioğluR. Risk Factors for Chronic Kidney Disease: An Update. Kidney Int Suppl. 2013; 3: 368371. Ref.: https://goo.gl/2dMuVf

22. Yacoub R, Habib H, Lahdo A, Al Ali R, Varjabedian L, et al. Association between Smoking and Chronic Kidney Disease: A Case Control Study. BMC Public Health. 2010; 10: 731. Ref.: https://goo.gl/Ca8KPU

23. Orth SR. Smoking and the Kidney. JASN. 2002; 13: 1663-1672. Ref.: https://goo.gl/bDTt93

24. Baumgarten M, Gehr T. Chronic Kidney Disease: Detection and Evaluation. American Family Physician. 2011; 84: 1138-1148. Ref.: https://goo.gl/BgUr8M

25. Woodhouse S, Batten W, Hendrick H, Malek PA. The Glomerular Filtration Rate: An Important Test for Diagnosis, Staging, and Treatment of Chronic Kidney Disease. Laboratory Medicine. 2015; 37 244-246. Ref.: https://goo.gl/38aakC

26. Coresh J, Astor BC, Greene T, Eknoyan G, Levey AS. Prevalence of Chronic Kidney Disease and Decreased Kidney Function in the Adult US Population: Third National Health and Nutrition Examination Survey. Am J Kidney Dis. 2003; 41: 1-12. Ref.: https://goo.gl/nJ5a4K

27. Lindeman RD, Tobin J, Shock NW. Longitudinal Studies on the Rate of Decline in Renal Function with Age. J Am Geriatr Soc. 1985; 33: 278-285. Ref.: https://goo.gl/nyo1nN

28. Turin TC, James M, Ravani P, Tonelli M, Manns BJ, et al. Proteinuria and Rate of Change in Kidney Function in a Community-Based Population. J Am Soc Nephrol. 2013; 24: 1661-1667. Ref.: https://goo.gl/SKBQ1B

29. Pounds LL, Teodorescu VJ. Chronic Kidney Disease and Dialysis Access in Women. J Vasc Surg. 2013; 57: 49S-53S. Ref.: https://goo.gl/uQX5nw

30. Kovesdy CP, Anderson JE, Kalantar-Zadeh K. Paradoxical Association between Body Mass Index and Mortality in Men with CKD Not yet on Dialysis. Am J Kidney Dis. 2007; 49: 581-591. Ref.: https://goo.gl/VJs2he 
31. Fouad M, Ismail MI, Gaballah A, E Reyad, ELdeeb S. Prevalence of Obesity and Risk of Chronic Kidney Disease among Young Adults in Egypt. Indian J Nephrol. 2016; 26: 413-418. Ref.: https://goo.gl/tbWnHM

32. Kovesdy CP, Furth SL, Zoccali C, World Kidney Day Steering Committee. Obesity and Kidney Disease: Hidden Consequences of the Epidemic. Nephron. 2017; 135: 243-251. Ref.: https://goo.gl/EZUuUf

33. Mallamaci F, Tripepi G. Obesity and CKD Progression: Hard Facts on Fat CKD Patients. Nephrol Dial Transplant. 28(suppl_4): iv105-iv108. Ref.: https://goo.gl/xZoANq

34. Blüher M. Are There Still Healthy Obese Patients? Current Opinion in Endocrinology. Diabetes and Obesity. 2012; 19: 341-346. Ref.: https://goo.gl/ckbz1z

35. Lopez-Giacoman S, Madero M. Biomarkers in Chronic Kidney Disease, from Kidney Function to Kidney Damage. World J Nephrol. 2015; 4: 57-73. Ref.: https://goo.gl/8z183s

36. Abcar AC, Chan L, Yeoh H. What To Do for the Patient with Minimally Elevated Creatinine Level? Perm J. 2004; 8: 51-53. Ref.: https://goo.gl/1CE9v3

37. Lin CC, Li Cl, Liu CS, Lin WY, Lin CH, et al. Development and Validation of a Risk Prediction Model for End-Stage Renal Disease in Patients with Type 2 Diabetes. Sci Rep. 2017; 7: 10177. Ref.: https://goo.gl/MxtHcN

38. Veerappan I, Abraham G. Chronic Kidney Disease: Current Status, Challenges and Management in India. Ch. 2013; 130: 593-597. Ref.: https://goo.gl/D763yt

39. Weiner DE, Tighiouart H, Amin MG, Stark PC, MacLeod B, et al. Chronic Kidney Disease as a Risk Factor for Cardiovascular Disease and All-Cause Mortality: A Pooled Analysis of Community-Based Studies. J Am Soc Nephrol. 2004; 15: 1307-1315. Ref.: https://goo.gl/KkEj5z 